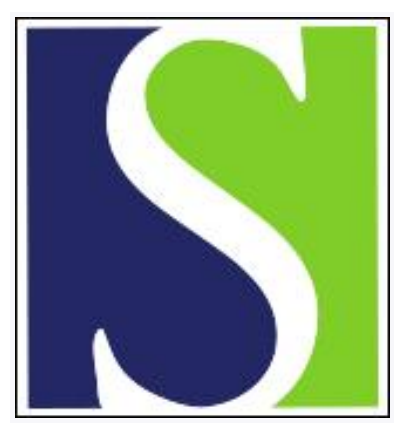

Scand J Work Environ Health 1996;22(1):66

https://doi.org/10.5271/sjweh.112

Issue date: Feb 1996

Testicular cancer in pesticide applicators in Swedish agriculture

by Dich J

This article in PubMed: www.ncbi.nlm.nih.gov/pubmed/8685678

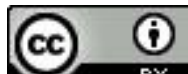




\section{Testicular cancer in pesticide applicators in Swedish agriculture}

Testicular cancer is more common in developed countries, and the incidence is highest in northern Europe and Canada (1). In Sweden the age-standardized incidence of testicular cancer almost doubled from 1960 to 1992, with an average annual increase of approximately $2.8 \%$ (1973-1992). In 1992, 225 new cases were reported to the Swedish Cancer Registry (2). Little is known about the etiology although the rising incidence during the last few decades, preferably among persons under the age of 40 years, together with data from migrant populations suggest a role for environmental factors $(1,3)$.

An increased risk of testicular cancer has been reported for populations with agricultural occupations $(4,5,6)$, whereas others have failed to observe such an association $(7,8,9)$. The incidence of seminomas and teratomas is higher for rural than for urban areas $(10,11)$

Exposure to pesticides or other agricultural chemicals has been suspected to increase the risk of testicular cancer. In a Swedish study (12) of 20025 licensed pesticide applicators in agriculture, who are more exposed to agricultural chemicals than farmers in general, a nonsignificantly increased risk was observed until 1982 for testicular cancer with 18 observed cases versus 11.6 expected [standardized incidence ratio (SIR) 1.55, 95\% confidence interval $(95 \%$ CI) $0.92-2.45]$. In this closed cohort all the cases after the time of license have been included. The cohort has now been followed in the Swedish Cancer Register until death or 31 December 1991, and the mean follow-up time was 21 years. Twenty-one cases were observed versus 19.2 expected (SIR 1.09, 95\% CI $0.68-1.67$ ), and no significantly increased risk for testicular cancer was thus found. For those born in 1935 or later, the SIR was 1.02 (95\% CI $0.54-1.74)$, and for those born before 1934, the SIR was $1.42(95 \%$ Cl $0.61-2.80)$.

This study failed to show any increased risk of testicular cancer among licensed pesticide applicators. Since the number of cases was small, care should be taken when conclusions are drawn from the results.

\section{References}

1. Horwich A, Mason MD, Hendry WF. Testicular tumours. In: Peckham M, Pinedo H, Veronesi U, editors. Oxford textbook of oncology; vol 2. Oxford (England): Oxford University Press, 1995:1407-39.

2. The National Board of Health and Welfare. Cancer incidence in Sweden 1992. Stockholm: The Swedish Cancer Registry, Centre for Epidemiology, Health and Diseases, 1995:1.

3. Hayes RB, Morris Brown L, Pottern LM, Gomez M, Karduan JWPF, Hoover RN, et al. Occupation and risk for testicular cancer: a case-control study. Int J Epidemiol 1990;19:825-31.

4. Graham S, Gibson RW. Social epidemiology of cancer of the testis. Cancer 1972;29:1242-9.

5. Mills PK, Newell GR, Johnson DE. Testicular cancer associated with employment in agriculture and oil and natural gas extraction. Lancet 1984;1:207-10.

6. McDowall ME, Balarajan R. Testicular cancer mortality in England and Wales 1971-1980: variations by occupation. J Epidemiol Community Health 1986;40:26-9.

7. Olsen JH, Jensen OM. Occupation and risk of cancer in Denmark: an analysis of 93810 cancer cases, $1970-1979$. Scand J Work Environ Health 1987;13 suppl 1:1 $\rightarrow$ 91.

8. van den Eeden SK, Weiss NS, Strader CH, Daling JR. Occupation and the occurrence of testicular cancer. Am J Ind Med 1991;19:327-37.

9. Wiklund K, Dich J. Cancer risks among male farmers in Sweden. Eur J Cancer Prev 1995;4:81—90.

10. Lipworth L, Dayan AD. Rural preponderance of seminoma of the testis cancer. Cancer 1969;23:1119-21.

11. Talerman A, Kaaleen JG, Fokkens W. Rural preponderance of testicular neoplasms. Br J Cancer 1973;27:176-8

12. Wiklund K, Dich J, Holm L-E. Testicular cancer among agricultural workers and licensed pesticide applicators in Sweden [letter]. Scand J Work Environ Health 1986;12:630 - 1.

Jan Dich, MSc, ${ }^{1}$ Kerstin Wiklund, PhD, ${ }^{1}$ Lars-Erik Holm, MD

1 Department of Cancer Epidemiology

Radiumhemmet

Karolinska University Hospital

S-171 76 Stockholm

Sweden

2 National Institute of Public Health

PO Box 27848

S-115 93 Stockholm

Sweden 